\title{
Men as partners in maternal health: an analysis of male awareness and attitude
}

\author{
Harkiran Narang ${ }^{1}$, Seema Singhal ${ }^{1,2} *$
}

\begin{abstract}
${ }^{1}$ Department of Obstetrics and Gynaecology, Lady Hardinge Medical College, New Delhi, India
${ }^{2}$ Presently at Department of Obstetrics and Gynaecology, Vardhman Mahavir Medical College and Safdarjang Hospital, New Delhi, India
\end{abstract}

Received: 21 April 2013

Accepted: 10 May 2013

\section{*Correspondence:}

Dr. Seema Singhal,

E-mail: drseemasinghal@gmail.com

(C) 2013 Narang $\mathrm{H}$ et al. This is an open-access article distributed under the terms of the Creative Commons Attribution Non-Commercial License, which permits unrestricted non-commercial use, distribution, and reproduction in any medium, provided the original work is properly cited.

\begin{abstract}
Background: Men remain an authority in all the aspects of reproductive health from policy making to its implementation at grass root level. Present study was conducted to determine the awareness and participation of men in maternal health care and to assess their attitude towards their partners.

Methods: We conducted a study in which 232 husbands accompanying their wives for delivery in teaching hospital of a metropolitan city were interviewed using a questionnaire. The questions were framed to assess their attitude, knowledge and participation in pregnancy care and maternal health

Results: $61 \%$ of participants had accompanied their wives to the antenatal clinics at one or the other time. However despite of coming to hospital $60.1 \%$ were not aware of the components of antenatal care like number of tetanus immunizations or requirements of increased diet during pregnancy. $44 \%$ of the men did not approve of their wives working outside home. $30 \%$ of the men admitted to have physically abused their partner on single or multiple occasions. $31 \%$ of the pregnancies were unplanned. $75.7 \%$ of the men thought that ideal family size comprises of two children. Only $36.2 \%$ of the men knew that male sterilization was safer than female sterilization.

Conclusion: Men in India have been marginalized in the dispense of antenatal and reproductive health care with policies emphasizing on the services and infrastructure more than involving men as responsible partners. Changes in men's and women's knowledge, attitudes and behavior are necessary conditions required in achieving the millennium development goals.
\end{abstract}

Keywords: Maternal health awareness, Male attitude, Knowledge, Behaviour

\section{INTRODUCTION}

Men play a key role in most societies. They still remain an authority in decision making in matters ranging from the size of families to the policy and programme at all levels.

Attention to men's involvement in reproductive health received an impetus following the "Programme of action" forged at the 1994 International Conference on Population and Development in Cairo. ${ }^{1}$ It was understood that special efforts should be made to emphasize shared responsibility of men and their active involvement in responsible parenthood, sexual and reproductive behavior, including family planning; prenatal, maternal and child health. Thus the United Nations Population Fund (UNFPA) has actively promoted male participation as a key to the achievement of maternal health goals and standards of care. ${ }^{1}$

It is now clear that the target of reducing maternal deaths by 75 per cent by 2015 (Millennium development goals) will not be met without the concerted efforts of all involved. Men, as partners, fathers, husbands, policy 
makers and community leaders have a critical role to play in safeguarding the health of women during pregnancy and beyond. ${ }^{2}$

Unfortunately there is a much smaller body of literature on male involvement that specifically examines their role in reducing maternal mortality and ensuring safe mother hood. As prospective fathers, husbands are likely to be more intimately involved in their wife's pregnancy and childbirth. Yet we know little about how involved they are when it comes to complete maternal care. ${ }^{3}$

Involving husbands and encouraging joint decisionmaking in reproductive and family health may provide an important strategy in achieving maternal health goals. ${ }^{4}$

It is, therefore, important to examine the involvement of men in maternal healthcare during pregnancy and childbirth in a developing country setting like India.

\section{METHODS}

The present study was conducted in a teaching hospital, for a period of 6 months. 232 men visiting the hospital for delivery of their spouse were randomly interviewed with the help of a questionnaire. An informed written consent was obtained from all the participants. Demographic details of participants were noted including age, education, income and type of family. The level of education was recorded in terms of number of years of schooling. The monthly income was stratified into four categories of 1) less than Rs.5000 (100\$) 2) Rs.5001-10, 000, 3) Rs.10, 000-20,000, 4) more than Rs.20, 000. We also asked them whether they lived in joint or nuclear families and who was the decision maker in the family. We also interviewed these men regarding their awareness of antenatal, postnatal care and attitude towards their partner's autonomy and health. They were questioned regarding their perception of the importance of antenatal care and whether they accompanied their wives during her visit to antenatal clinic. Their knowledge about tetanus immunizations, increased dietary requirement in pregnancy was also assessed. Perception of participants regarding importance of postnatal care was also recorded. We asked if they felt that postpartum contraception for birth spacing was important and when should it start. We asked whether they were comfortable with their wives working outside home, their preference for a male child, or if they would like to know the sex of their unborn child and would that affect them in taking decisions relating to the care during pregnancy. We asked them if they would discriminate between their sons and daughters when giving them education opportunities. We also questioned them whether their present child was planned or unplanned, their idea of ideal family size and their acceptance of male sterilization as an option. We analyzed behavior and practices of men like accompanying their wife to antenatal clinic, planning pregnancy, approving their wife working outside homes. We also questioned them if they ever been violent with their partners and analyzed the prevalence of domestic violence against the years of schooling of the husbands, their income and years of marriage. The associations between various qualitative variables were obtained using chi square test. The quantitative variables were related to the categorical variables using unpaired t test and ANOVA. The analysis was done using SPSS version 15.0.

\section{RESULTS}

The mean age of the men interviewed was $29.66 \pm 3.498$ yrs. 204 men were from hindu community, 22 from muslim, four were from sikh community and two from Christian. Mean years of schooling of the men was 9.31 \pm $4 y r s$. Average duration of married life of participants was $4.76 \pm 3.99$ yrs. Average monthly income of participants was also stratified and it was seen that $27.6 \%$ had average monthly income of $<$ Rs 5000. And $25.8 \%$ were earning Rs 5000-10,000. 13.8\% of men were earning Rs 10,00020,000 per month. $32.8 \%$ of men were earning $>$ Rs 20,000 per month. $60.3 \%$ were living in joint families and $39.7 \%$ were from nuclear families. It was observed that majority i.e. $69 \%$ of couples had planned pregnancies in the study. However men were found to have higher level of education in the planned pregnancy group than the group where pregnancies were unplanned, although this difference was not found to be statistically significant. (mean years of schooling $9.51 \pm 4$ years Vs $8.89 \pm 4.2$ years, $\mathrm{p}=0.06$ ). $61 \%$ of husbands accompanied their wives to antenatal clinic. On analysis we found that the husbands who were accompanying their wives to hospital for antenatal visits were more recently married as compared to those who didn't accompany (mean years of married life $=1.26 \pm 0.89 \mathrm{Vs} 3.69 \pm 2.58$ years, $\mathrm{p}$ value $=0.002$, unpaired t test). $40.6 \%$ of the men who were earning less than Rs.5000 per month and $53.3 \%$ of the men who were earning Rs 5000 to 10,000 per month did not accompany their wives to antenatal clinics. On the other hand $28.9 \%$ of men who were earning more than Rs 20,000 per month did not accompany their wives to antenatal clinic. Their per month income was not significantly related with their visit to antenatal clinics with their wives. When assessed in relation to the mean years of schooling we found that men who didn't accompany their wives for antenatal visits had lower mean level of education than their other counterparts $(8.61 \pm 2.973$ Vs 9.94 \pm 3.809 , p value $=0.109)$. We also observed that despite of coming to hospital men were not directly included into antenatal care. It was seen that $60.1 \%$ of those men who accompanied their wives to hospital for antenatal care were not even aware of the number of Tetanus immunizations needed in pregnancy. $30.1 \%$ of the men thought that antenatal care was not required till three months of pregnancy and $64.7 \%$ of the men interviewed were not aware of their wife's diet during pregnancy or looked into the adequacy of it. $91.4 \%$ of the men perceived postnatal care to be important but $75 \%$ of the interviewed men did not know when postpartum contraception should start. $36.2 \%$ knew that male sterilization is safer than female sterilization but $38 \%$ of these men prefer female sterilization if given a 
choice. In present study we observed that out of 232 pregnancies $69 \%$ were planned and $31 \%$ were unplanned. In the couples where the pregnancy was planned the mean years of schooling of the husband was $9.51 \pm 4$ years .In the other group where pregnancies were unplanned, the men had a lower mean years of schooling i.e. $8.89 \pm 4.2$ yrs. But this difference was not found to be statistically significant $(p=0.37)$. There was no correlation with the years of marriage or the presence of addictions or the type of family (joint or nuclear). In our study $44 \%$ of the men did not approve of their wives working outside home.

The mean year of schooling was higher in men approving of their wives working. (9.72 \pm 4.11 vs. $8.80 \pm 4.03)$ as compared to the men who didn't approve, but this difference did not reach statistical significance. $(p=0.231)$. Income was the main factor governing the men's approval of their wives working outside. $56.3 \%$ of the men earning less than Rs 5000 per month and $53.3 \%$ of the men earning 5000 to 10,000 per month did not approve of their wives working as compared to $34.2 \%$ of the men earning more than Rs 20,000 per month. The proportion of men approving of their wives working outside or accompanying their wives to antenatal clinic was significantly more in men earning $>10,000$ per month as compared to those earning lesser $(\mathrm{p}=0.05)$.

Regarding perception of ideal family size, $75.7 \%$ of the men in the present study thought that the ideal family size comprises of two children. However, $50.6 \%$ of these men admitted that despite of this knowledge they would have more children if there was no male child in the family. $95.2 \%$ of the men who said that the choice of having more children depends on presence of a male child in the family and $79.2 \%$ of them were earning less than Rs. 10,000 per month.

In present study it was observed that about $29.3 \%$ wanted to know the sex of their child antenatal if given the option. $47 \%$ of these were earning Rs 10,000 and more per month and $53 \%$ were earning less than Rs 10,000 per month. $30 \%$ of the men admitted to have physically abused their partner on single or multiple occasions during pregnancy.

Association between the level of education and domestic violence was significant $(\mathrm{p}$-value $=0.002)$ with higher level of domestic violence prevalent in less education groups. Domestic violence was also significantly $(\mathrm{p}<0.001)$ more in middle-income groups (income between Rs 5,000-10,000 per month). There was no significant association with the type of family, family size, addiction in husband, years of married life or the age difference between the husband and wife.

\section{DISCUSSION}

There is an increasing need to involve men in improving the reproductive health status of women. ${ }^{1}$ National Population Policy of India also emphasises the need to focus on men to promote the small family norm. ${ }^{5}$ Surveys around the world increasingly are interviewing men and reporting regarding their role in the reproductive health of women. ${ }^{6}$ The most prominent barriers to male involvement in maternal health include low levels of knowledge, shyness and job responsibilities. ${ }^{7}$

In this study the men who didn't accompany their wives to antenatal clinics thought it was not their business to do so as it was a "women's affair". They did not see themselves as a part of the antenatal care process. The men who accompanied their wives felt that they were not accommodated in the system, as joint consultations were not allowed. As a result $60.1 \%$ of those who accompanied their wives, were not even aware of the number of tetanus immunizations required in pregnancy .The antenatal advice given to the women was not passed on to the accompanying husband either due to lack of his interest or understanding in the matter.

A survey analysis in Maharashtra, India showed that men were generally knowledgeable but were excluded from participating in routine care because the medical system did not accommodate them. Despite high awareness and a professed sense of responsibility the extent to which husbands were present at routine antenatal or postnatal care or at delivery was limited. ${ }^{8}$

Whether a non-accommodating system is the reason for some men not coming to antenatal clinics remains to be explored. But in our study when these men were asked if they took interest in their wife's diet during pregnancy, more than half $(64.7 \%)$ admitted to not having looked into the adequacy of it. This highlights a sense of reluctance to get involved in the pregnancy care, which almost all the participants admitted also, during the questionnaire. It was seen that this sense of reluctance is more in men having a higher number of years of married life, and in men having a lower income and education. Therefore we could see that education of men was the most important factor governing the involvement of men into their wives health.

Responsible parenthood includes planning family size and avoiding unwanted pregnancies. In our study men who accompanied their wife in antenatal clinics had a relatively higher level of education and were more likely to have a planned pregnancy $(69 \%)$.However, planning their pregnancy was not related to the ultimate family size as some men admitted to want more children till they had at least one male child. This attitude was irrespective of their knowledge of an ideal family size and was more in men already having a relatively higher number of children. Observational studies suggest that including men in reproductive health interventions can enhance positive health outcomes. ${ }^{9}$ Studies have found that involving husbands in antenatal care counseling significantly increases the frequency of antenatal care visits and their knowledge about family 
planning, nutrition and health of their wives during pregnancy. ${ }^{9-11}$

Studies in past assessing the impact of women's autonomy on maternal health care utilization in India, have shown that those women with greater freedom of movement obtained higher levels of antenatal care and were more likely to use safe delivery care. ${ }^{12}$

Regarding employment educated men felt that their wives could work. Relatively fewer years of schooling and consequent lower monthly income was related to husbands not wanting their wives to work outside homes. $48 \%$ men living in nuclear families in our study said that they were the sole decision makers in all matters of the household and those related to health of their wives. It was interesting to note that relatively low education was also associated with violent behavior towards the partner. $33 \%$ of the men interviewed admitted to have been violent with their partners on single or multiple occasions. In the present study we found a higher level of domestic violence prevalent in less education groups and in middle-income groups (income between Rs.500010000 per month).

There was no correlation between the prevalence of domestic violence and type of family or husband's addiction to alcohol, smoking or drugs. This is unlike many studies that frequently report high rates of alcohol and other drug involvement in association with domestic violence. ${ }^{13-15}$ This difference could be attributed to the heterogeneity of the population studied and shyness of husbands to admit.

Among the different types of gender-based violence, domestic violence is the most common type prevalent in India. ${ }^{16-18}$ According to the National Family and Health Survey-2 (NFHS-2), $21 \%$ of ever-married women in India have been physically mistreated by their husbands, in-laws or other members of the household. ${ }^{19}$ Evidences from population-based surveys suggest that between 21 to $48 \%$ of women from different socio-cultural settings in India have experienced domestic violence. ${ }^{20}$

Prenatal sex determination followed by selective abortion of female fetuses is the most plausible explanation for the low sex ratio at birth in India. ${ }^{21}$ In the present study $29.3 \%$ of the men interviewed said that they would like to find out if their wives were carrying a male child before birth. $47 \%$ of these were earning Rs 10,000 and more per month and $53 \%$ were earning less than Rs 10,000 per month.

Myths regarding safety of male sterilization are still prevalent in our society. Only about a third (36.2\%) of the interviewed men felt that male sterilization is safer than female sterilization but $38 \%$ of these men would have still opted for female sterilization if given the choice. Some men reported negative attitudes toward vasectomy, sharing many stories of times when the procedure had not worked or had resulted in physical weakness, thus limiting a man's ability to be a bread winner for his family. Fears about weakness resulting from the procedure were common and served as one of the main barriers to acceptance for vasectomy. This is supported by findings of other studies analyzing the acceptance of male sterilization. ${ }^{22-24}$ Timely initiation of contraception in the post-partum period can be very important in avoiding unplanned pregnancies. Only $8.6 \%$ of the men interviewed felt that postpartum care or follow-up was not important but interestingly majority of them $(60 \%)$ were also violent partners. Three fourth (75\%) of interviewed men did not know when postpartum contraception should start. This was irrespective of the level of education.

This study makes it clear that there remains a lot to be achieved towards the understanding of antenatal, postnatal care, contraceptive choices and autonomy by married couples. We need to make health information accessible and understandable to all so as to help masses to make informed decisions and to properly utilize available services. Efforts to improve maternal health can then have a positive impact on women and their families.

International studies from a variety of regions have shown that reproductive health programs are likely to be more effective for women when men are involved in healthcare system in some way. ${ }^{25}$ These findings suggest that involving men in reproductive health interventions might help to foster a better understanding between husbands and wives, which in turn affect the utilization of services and maternal health of women. Ensuring men's involvement in reproductive and child health may be challenging from the programme perspective but it may provide an effective means to successfully translate a policy in programme of action.

\section{CONCLUSIONS}

Keeping in mind the family structure and limited autonomy women have in India, it is not surprising the men are like gatekeepers to maternal health care and safe motherhood.

We have yet to go a long way to achieve women empowerment. Our health care has to take into consideration the attitudes and awareness of males and make every effort to involve them as caring non-violent partners to improve maternal health. The responsibility of being parents starts much before the birth of the child.
Funding: None
Conflict of interest: None declared
Ethical approval: Not required 


\section{REFERENCES}

1. International Conference on Population and Development - ICPD - Programme of Action A/CONF.171/13/Rev.1 -- Report of the International Conference on Population and Development.

2. UNFPA- It Takes Two: Men as Partners in Maternal Health. http://www.unfpa.org/public/global/pid/84.

3. Barua A, Pande RP, Quarrie MK. Caring men? Husband's Involvement in Maternal Care of Young Wives. Economic and Political Weekly 2004; 39(52):5661-8.

4. Mullany BC, Hindin MJ,Beker S. Can women's autonomy impede male involvement in pregnancy health in Katmandu, Nepal? Soc Sci Med. 2005 Nov; 61(9):1993-2006.

5. Govt of India. National population policy. New Delhi: Ministry of Health and Family Welfare; 2000.

6. Salem R. Men's surveys: New Findings. Population Report. Series M No 18 Baltimore, Johns Hopkins Bloomberg School of Public Health. The INFO Project Spring. 2004.

7. Mullany BC. Barriers to and attitudes towards promoting husbands' involvement in maternal health in Katmandu, Nepal. Soc Sci Med. 2006 Jun;62(11):2798-809.

8. Singh, A. (2007): Male involvement in Family Planning and Maternal Care: Evidences from Rural Maharashtra Ph.D. Thesis (International Institute for Population Sciences, IIPS, Mumbai, India.

9. [9]Mullany BC, Becker S, Hindin MJ. The impact of including husbands in antenatal health education services on maternal health practices in urban Nepal: results from a randomized controlled trial. Health Educ Res. 2007 Apr;22(2):166-76.

10. Bhalerao VR, Galwankar M, Kowli SS, Kumar R, Chaturvedi RM. Contribution of the education of the prospective fathers to the success of maternal health care programme. J Postgrad Med. 1984 Jan;30(1):10-2.

11. Singh KK, Bloom SS.Tsui AO. Husbands' reproductive health knowledge, attitudes, and behavior in Uttar Pradesh, India. Stud Fam Plann. 1998 Dec;29(4):388-99.

12. Bloom SS,Wypij D,Das GM. Dimensions of women's autonomy and the influence on maternal health care utilization in a northen Indian city. Demography 2001 Feb;38:67-78.
13. Amaro H, Fried LE, Cabral H, Zuckerman B. Violence during pregnancy and substance use. Am J Public Health. 1990 May;80(5):575-9.

14. Berenson AB, Stiglich NJ, Wilkinson GS, Anderson GD. Drug abuse and other risk factors for physical abuse in pregnancy among white non-Hispanic, black, and Hispanic women. Am J Obstet Gynecol. 1991 Jun;164(6 Pt 1):1491-9.

15. Heise LL, Raikes A, Watts $\mathrm{CH}$, Zwi AB. Violence against women: a neglected public health issue in less developed countries. Soc Sci Med.1994 Nov;39(9):1165-79.

16. Stewart DE, Cecutti A. Physical abuse in pregnancy. CMAJ. 1993 Nov 1;149(9):1257-63.

17. Ghosh D. Predicting Vulnerability of Indian Women to Domestic Violence Incidents. Research and Practice in Social Sciences 2007 Aug;3(1):48-72.

18. Sharma N. Best Practices among Responses to Domestic Violence in Maharashtra and Madhya Pradesh. Women's Studies Unit, Tata Institute of Social Sciences: Mumbai. In Domestic Violence in India: A Summary Report of Three Studies. International Center for Research on Women: Washington, DC, September, 1999. 26-38.

19. IIPS, and Macro. 2000. National family Health Survey (NFHS-2), 1998-99: India. Mumbai: International Institute for Population Sciences.

20. INCLEN. 2000. Domestic Violence in India 3: A Summary Report of a Multi-Site Household Survey. Washington, DC: International Center for Research on Women and The Center for Development and Population Activities.

21. Jha P, Kumar R, Vasa P, Dhingra N, Thiruchelvam D, Moineddin R. Low female[corrected]-to-male [corrected] sex ratio of children born in India: national survey of 1.1 million households. Lancet. 2006 Jan 21; 367(9506):211-8.

22. Balaiah D, Naik DD, Parida RC, Ghule M, Hazari KT, Juneja HS. Contraceptive knowledge, attitude and practices of men in rural Maharashtra. Adv.Contracept.1999:15(3):217-34.

23. Ross JA, Huber DH. Acceptance and prevalence of vasectomy in developing countries. Stud Fam Plann. 1983 Mar;14(3):67-73.

24. Clift E. Redefining macho: men as partners in reproductive health. Perspect Health 1997;2(2):20-5.

25. Mbizvo MT, Bassett MT. Reproductive health and AIDS prevention in sub-Saharan Africa: the case for increased male participation. Health Policy Plan. 1996 Mar;11(1):84-92.

DOI: $10.5455 / 2320-1770 . i j r \operatorname{cog} 20130925$

Cite this article as: Narang $\mathrm{H}$, Singhal $\mathrm{S}$. Men as partners in maternal health: an analysis of male awareness and attitude. Int J Reprod Contracept Obstet Gynecol 2013;2:388-92. 